\title{
Combined pulmonary vein stenosis stenting and left atrial appendage occlusion in a patient with hemoptysis after atrial fibrillation ablation
}

\author{
Yan-Jie Li, Xin Pan ${ }^{*}$, Cheng Wang and Ben He
}

\begin{abstract}
Background: Pulmonary vein stenosis (PVS) after radiofrequency ablation for non-valvular atrial fibrillation (AF) is an uncommon but serious complication. PVS stenting can rapidly restore pulmonary flow and improve symptoms with long-term low incidence of restenosis. However, high risk of thrombosis remains if AF is recurrent, especially for $\mathrm{CHA}_{2} \mathrm{DS}_{2}-\mathrm{VASC}>2$.

Case presentation: A 67-year-old man with diabetes, hypertension and a history of stroke underwent radiofrequency pulmonary vein isolation for persistent AF 1 year ago. Six months later he developed recurrent respiratory infection and massive hemoptysis. Computed tomography pulmonary angiography revealed severe left pulmonary vein stenosis. Simultaneous percutaneous PVS stenting and left atrial appendage occlusion were performed to resolve recurrent hemoptysis and prevent stroke. The clinical follow-up indicated a good short and mid-term result with significant improvement of symptoms.
\end{abstract}

Conclusions: Simultaneous PVS stenting and left atrial appendage occlusion is feasible and effective in patients with recurrence of AF and hemoptysis induced by radiofrequency ablation for AF.

Keywords: Atrial fibrillation, Hemoptysis, Left atrial appendage occlusion, Pulmonary vein stenosis, Stenting

\section{Background}

Pulmonary vein stenosis (PVS) is an uncommon but potentially serious complication following catheter ablation for atrial fibrillation (AF) [1]. Obviously, in symptomatic cases with severe PVS, early PVS stenting is needed to restore pulmonary flow $[2,3]$. However, high risk of cardiac thrombosis remains if AF is recurrent. In such situations with co-existing bleeding complication, left atrial appendage occlusion (LAAO), currently regarded as a non-inferior alternative to anticoagulation in patients with non-valvular AF $[4,5]$, is useful to reduce the risk

\footnotetext{
* Correspondence: panxinchest@163.com

Department of Cardiology, Shanghai Chest Hospital, Shanghai Jiao Tong University, 241 West Huaihai Road, Shanghai 200030, China
}

of thrombosis and bleeding. Here, we report a case of simultaneous percutaneous PVS stenting and LAAO to resolve the dilemma.

\section{Case presentation}

A 67-year-old man with diabetes, hypertension and a history of stroke underwent radiofrequency pulmonary vein (PV) isolation for persistent AF 1 year ago. Six months later he developed recurrent respiratory infection and massive hemoptysis. Electrocardiogram showed recurrence of AF. Warfarin was initially started but discontinued due to hemoptysis. Metoprolol was used for rate control. Computed tomography pulmonary angiography

C C The Author(s). 2020 Open Access This article is licensed under a Creative Commons Attribution 4.0 International License, which permits use, sharing, adaptation, distribution and reproduction in any medium or format, as long as you give appropriate credit to the original author(s) and the source, provide a link to the Creative Commons licence, and indicate if changes were made. The images or other third party material in this article are included in the article's Creative Commons licence, unless indicated otherwise in a credit line to the material. If material is not included in the article's Creative Commons licence and your intended use is not permitted by statutory regulation or exceeds the permitted use, you will need to obtain permission directly from the copyright holder. To view a copy of this licence, visit http://creativecommons.org/licenses/by/4.0/ The Creative Commons Public Domain Dedication waiver (http://creativecommons.org/publicdomain/zero/1.0/) applies to the data made available in this article, unless otherwise stated in a credit line to the data. 
(CTPA) revealed severe left PV stenosis (Fig. 1a). He was admitted in our hospital for further treatment.

The patient was at high risk of AF-related stroke $\left(\mathrm{CHA}_{2} \mathrm{DS}_{2}-\mathrm{VASc}\right.$ score $\left.=5\right)$ and bleeding (HAS-BLED score $=3$ ). In addition, risk of PV re-stenosis and recurrence of hemoptysis made long-term oral anticoagulation unfavorable in this patient.

We thus attempted to combine percutaneous PVS stenting and LAAO to resolve the problem. For percutaneous PVS stenting, we started with left pulmonary artery wedge angiography and direct selective PV angiography. As a result, severe stenosis at the ostium of left superior and inferior PV were visualized. New vascular plexus distal to the stenosis was highly suspected as the source of hemorrhage (Fig. 1b, c). Step-by-step balloon dilation of the conduit was firstly performed, and then two relatively big bare metal stents $(9 * 25 \mathrm{~mm}$ and $8 * 27 \mathrm{~mm}$; Boston Scientific, Natick, Massachusetts, USA) were successfully deployed in the proximal left superior and inferior PV respectively. PV angiography demonstrated no residual stenosis, rupture or dissection of the lesion (Fig. 1d, e). The transstenotic pressure gradient was decreased from 22
$\mathrm{mmHg}$ to $0 \mathrm{mmHg}$. Pulmonary vein caliber was significantly increased from $2.1 \mathrm{~mm}$ to $8.5 \mathrm{~mm}$, and pulmonary artery pressure was decreased from $52 / 21 \mathrm{mmHg}$ (31 $\mathrm{mmHg})$ to $32 / 20 \mathrm{mmHg}(24 \mathrm{mmHg})$. For LAAO, a Watchman Double Curve Access System was advanced into left atrium (LA) over the guidewire. Left atrial appendage (LAA) angiography revealed the whole lobe (Fig. 1f), and the ostial diameter was measured to be $23-25$ $\mathrm{mm}$ by angiography and transesophageal echocardiography (TEE) views. Thereafter, a $30 \mathrm{~mm}$ Watchman occluder was deployed under fluoroscopy and TEE guidance (Fig. 1g, h). Once no significant peridevice leak was found and all release criteria were confirmed, the device was fully released. Heparin $(80 \mathrm{IU} / \mathrm{kg})$ was used during the procedure and activated clotting time was maintained as $250 \mathrm{~s}$ $350 \mathrm{~s}$.

After the procedure, the patient experienced immediate relief of symptoms. Then he received a combination of Aspirin and Clopidogrel for 6 months followed by Aspirin only indefinitely. The patient was followed at 3, 6 and 12 months. He remained asymptomatic without bleeding recurrence. CT scan was performed at 6 months and

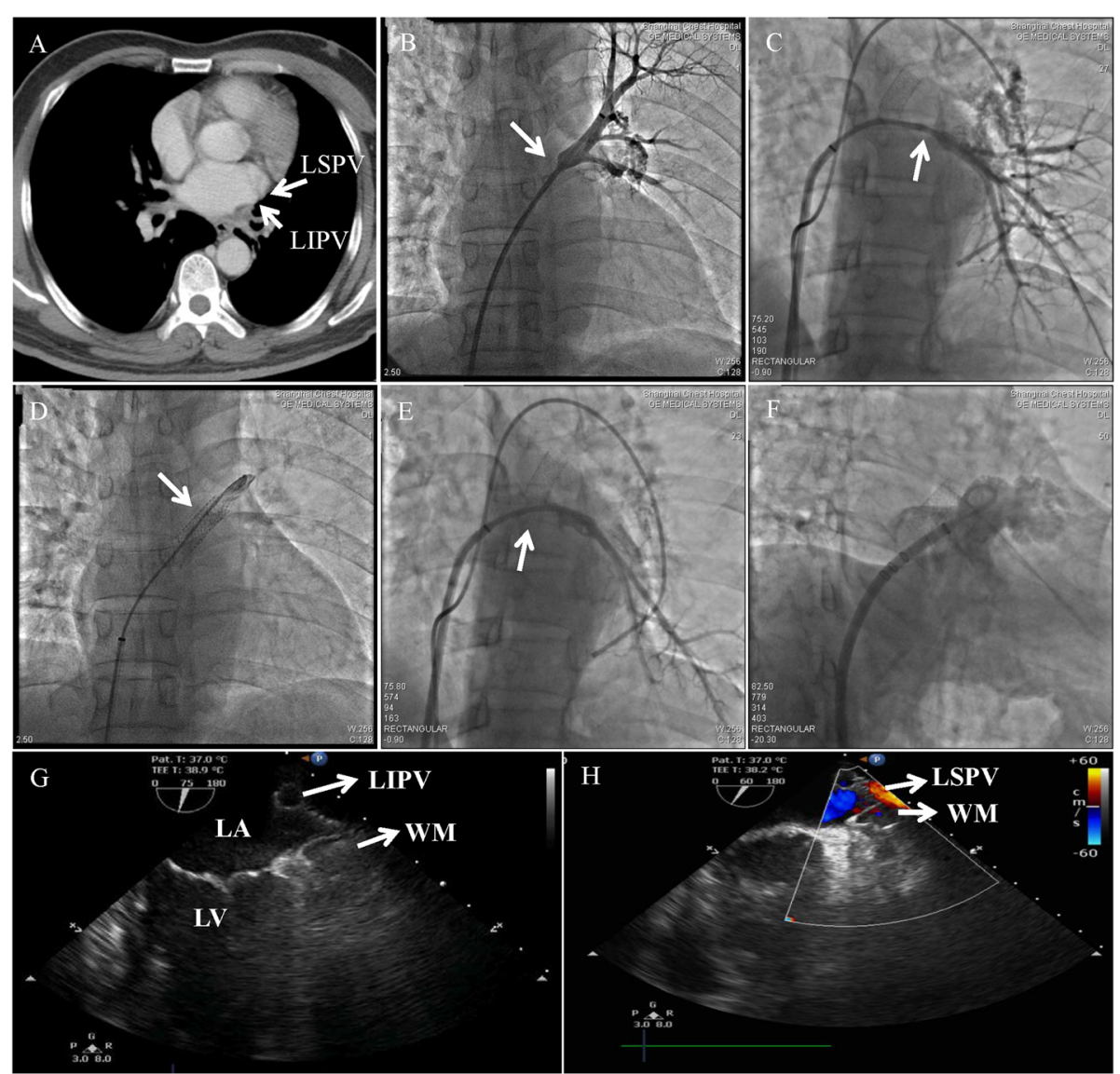

Fig. 1 a Subtotal stenosis of the left PV in CT scan. b, c PV angiography shows severe stenosis of the left PV (arrow) and plexiform vein collaterals before PV Stenting. d, e PV angiography shows patent stents with no residual stenosis (arrow) after PV Stenting. $\mathbf{f}$ Left atrial appendage angiography. g, h Partially deployed Watchman device 

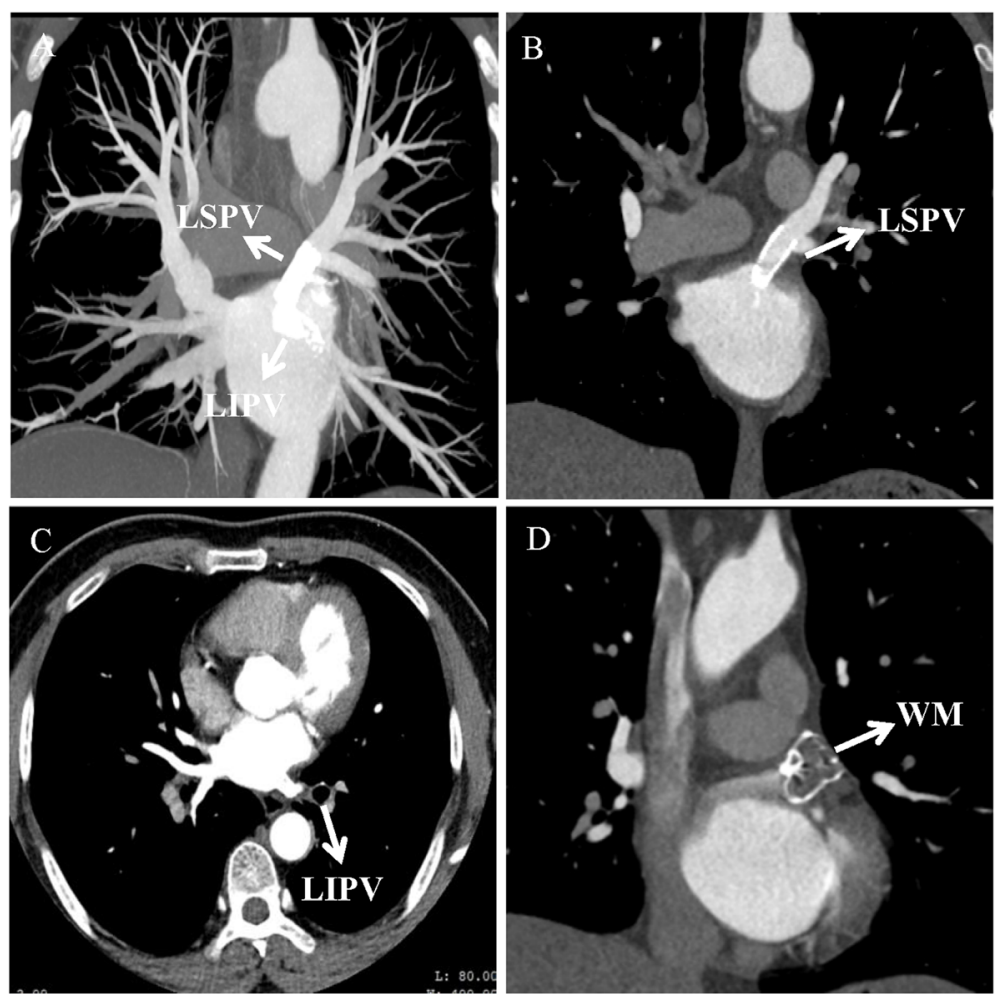

Fig. 2 a Restored pulmonary blood flow. b, c No in-stent restenosis. $\mathbf{d}$ No device-related thrombus in CT scan at 6 months post-procedure

showed restored pulmonary venous flow (Fig. 2a), no instent restenosis (Fig. 2b, c) and no device related thrombosis (DRT) with regard to Watchman (Fig. 2d).

\section{Discussion and conclusions}

PVS after radiofrequency ablation is an uncommon but serious complication [6]. In symptomatic cases, PVS stenting can provide hemodynamic relief of pulmonary circulation [2]. However, like our patient, who had a bleeding complication and relative contraindication to chronic oral anticoagulation with warfarin or NOACs, the potential risk of LAA thrombosis and concomitant stroke are challenging. Re-Do ablations are possible in PVS after stents implantation, but the clinical benefit should be carefully considered and ostial ablation should be avoided [7]. Thus, stroke prophylaxis is of significance in the situation. While this case is performed combining with LAAO, these risks could be substantially reduced [8].

The current case illustrates the safety and feasibility of simultaneous PVS stenting and LAAO in such situation. Our experience of this procedure is that PV stenting should be first successfully performed; left superior PV stent should not be placed too close to the LA body. Sequentially, the Watchman Access Sheath should be advanced slowly to avoid interfering with PV stent.
In conclusion, the strategy of PVS stenting combined with LAAO can solve the dilemma of bleeding and thromboembolism. During the procedure, we deployed the large stent in the stenotic PV followed by dual antiplatelet therapy per the ASAP registry regimen [9]. The patient had good short and mid-term results upon follow up.

\section{Abbreviations}

AF: Atrial fibrillation; CT: Computed tomography; CTPA: Computed tomography pulmonary angiography; DAPT: Dual antiplatelet therapy; DRT: Device-related thrombus; LA: Left atrium; LAAO: Left atrial appendage occlusion; LIPV: Left inferior pulmonary vein; LSPV: Left superior pulmonary vein; LV: Left ventricle; PV: Pulmonary vein; PVS: Pulmonary vein stenosis; TEE: Transesophageal echocardiography; WM: Watchman

\section{Acknowledgments \\ Not applicable.}

\section{Authors' contributions}

$Y-J L, X P$, and $C W$ collected the data, made the figures, interpreted results, and drafted the manuscript. BH edited the manuscript, participated in the conception and design of study. All authors read and approved the final manuscript.

\section{Funding}

This study was partly supported by grants from the Shanghai Committee of Science and Technology, China (17411970900 and 18411950400) and the State Key Program of National Natural Science of China (81830010). The funding bodies played no role in the design of the study and collection, analysis, and interpretation of data and in writing the manuscript. 
Availability of data and materials

Not applicable.

Ethics approval and consent to participate

Not applicable.

\section{Consent for publication}

Written informed consent was obtained from the study participant.

\section{Competing interests}

All the authors declare no potential conflict of interest.

Received: 13 February 2020 Accepted: 12 April 2020

Published online: 22 April 2020

\section{References}

1. Yu D, Jie B, Li LL, Jiang S. Bilateral pulmonary vein stenting for treatment of massive hemoptysis caused by pulmonary vein stenosis following catheter ablation for atrial fibrillation. BMC Cardiovasc Disord. 2019;19(1):162.

2. Li YJ, Pan X, Wang C, He B. Stent implantation for severe pulmonary vein stenosis or occlusion secondary to atrial fibrillation ablation. Int J Cardiol. 2020:301:85-9

3. Fender EA, Widmer RJ, Hodge DO, Packer DL, Holmes DR Jr. Assessment and management of pulmonary vein occlusion after atrial fibrillation ablation. JACC Cardiovasc Interv. 2018;11(16):1633-9.

4. Glikson M, Wolff R, Hindricks G, Mandrola J, Camm AJ, Lip GYH, et al. EHRA EAPCl expert consensus statement on catheter-based left atrial appendage occlusion - an update. Eurolntervention. 2020;15(13):1133-80.

5. Fastner C, Hoffmann L, Aboukoura M, Behnes M, Lang S, Borggrefe M, et al. Real-world experience comparing two common left atrial appendage closure devices. BMC Cardiovasc Disord. 2018;18(1):171.

6. Padala SK, Ellenbogen KA. Pulmonary vein stenosis after atrial fibrillation ablation: an iatrogenic problem larger than the primary problem. Circ Arrhythm Electrophysiol. 2018;11(5):e006461.

7. Raeisi-Giglou P, Wazni OM, Saliba WI, Barakat A, Tarakji KG, Rickard J, et al. Outcomes and management of patients with severe pulmonary vein stenosis from prior atrial fibrillation ablation. Circ Arrhythm Electrophysiol. 2018;11(5):e006001.

8. Reddy WY, Doshi SK, Kar S, Gibson DN, Price MJ, Huber K, et al. 5-year outcomes after left atrial appendage closure: from the PREVAIL and PROTECT AF trials. J Am Coll Cardiol. 2017;70(24):2964-75.

9. Sharma D, Reddy VY, Sandri M, Schulz P, Majunke N, Hala P, et al. Left atrial appendage closure in patients with contraindications to oral anticoagulation. J Am Coll Cardiol. 2016;67(18):2190-2.

\section{Publisher's Note}

Springer Nature remains neutral with regard to jurisdictional claims in published maps and institutional affiliations.

Ready to submit your research? Choose BMC and benefit from:

- fast, convenient online submission

- thorough peer review by experienced researchers in your field

- rapid publication on acceptance

- support for research data, including large and complex data types

- gold Open Access which fosters wider collaboration and increased citations

- maximum visibility for your research: over $100 \mathrm{M}$ website views per year

At BMC, research is always in progress.

Learn more biomedcentral.com/submissions 